\title{
RESULTADOS DE LAS INVESTIGACIONES PALEOPATOLÓGICAS EN HOMÍNIDOS FOSILES
}

\author{
Pilar Julia PÉREZ1 \\ ' Dpto. y UEI de Paleontología. Facultad de CC. Geológicas e Instituto de Geología Económica. UCM- CSIC, 28040 Madrid.
}

Pérez, P. J. 1996. Resultados de las investigaciones paleopatológicas en homínidos fósiles. [Rèsults of the paleopathologic research in fossil hominids]. Revista Española de Paleontología, Nºxtraordinario, 256-268. ISSN 0213-6937.

\begin{abstract}
A compilation of paleopathological diagnosis on fossil hominids and some facts on Holocene prehistoric populations are contained in this work. The important role of the Paleopathology in order to decipher human life conditions in the past is reflected in this synthesis.
\end{abstract}

Keywords: Paleoepidemiology, intraspecific violence, natural accidents, skeletal modifications of cultural origin, taphonomy.

\section{RESUMEN}

\begin{abstract}
Este trabajo contiene una recopilación de diagnósticos paleopatológicos emitidos sobre homínidos fósiles, y datos referidos a poblaciones prehistóricas del Holoceno. Esta visión de conjunto refleja la importancia de la Paleopatología para descifrar condiciones de vida humana en el pasado.
\end{abstract}

Palabras clave: Paleoepidemiología, violencia intraespecífica, accidentes naturales, modificaciones esqueléticas de origen cultural, tafonomía.

\section{INTRODUCCIÓN}

El estudio paleopatológico de homínidos fósiles se concibe actualmente como una fuente de información de primera magnitud para descifrar condiciones de vida de nuestros antepasados y parientes más próximos. En múltiples ocasiones dicho estudio ha permitido valorar, con mayor aproximación y fiabilidad, el grado de influencia que muchas variables medioambientales, y especialmente culturales, han ejercido sobre el estado físico de los individuos de una población. El uso integrado de la paleopatología, donde el perfil paleopatológico se conjuga con el antropológico y el conjunto del registro arqueológico, nos proporciona valiosos datos sobre aspectos muy concretos de la biología de antiguos homínidos, como adaptación al medio, mecanismos naturales de defensa, por ejemplo frente a la carga patogénica del ambiente, y sobre su etología, como estrategias de subsistencia, agresividad, o comportamiento altruista.

La bibliografía sobre paleopatología de homínidos fósiles es ya muy copiosa. En su evolución, esta línea de investigación ha pasado por una fase de mera descripción de modificaciones óseas y dentarias observadas con ocasión del estudio paleoantropológico de piezas anatómicas, donde se sugerían uno o más posibles diagnósticos. Posteriores estudios de revisión y aplicación de nuevas técnicas han permitido confirmar o rectificar diagnósticos, avalados ahora por sólidas evidencias. En los estudios sobre morbilidad y mortalidad en antiguos homínidos es necesario tener presente que los individuos analizados no necesariamente representan una misma población biológica; no obstante, y a pesar de las limi- taciones impuestas por las muestras, se han obtenido grandes logros en los estudios paleoepidemiológicos de homínidos fósiles, como queda reflejado en la recopilación de diagnósticos médicos retrospectivos contenidos en este trabajo. Esta recopilación incluye, además de homínidos fósiles, datos referidos a poblaciones prehistóricas del Holoceno.

\section{DIAGNÓSTICOS MÉDICOS RETROSPECTIVOS}

\section{YACIMIENTOS PLIO-PLEISTOCENOS/ PLEISTOCENOS INFERIOR}

Recientemente White et al. (1993) han aportado el dato más antiguo de artropatía degenerativa temporomandibular en homínidos; concretamente entre los nuevos hallazgos de Australopithecus afarensis de Maka (Etiopía), cuya edad se ha estimado en 3,4 Ma. Las lesiones osteoartríticas se presentan en los dos cóndilos de la mandíbula más completa conocida de homínidos mesopliocenos: MAK-VP1/12, que conserva las piezas dentarias a excepción de I1 inferior izquierdo y de I1, I2 y C inferiores derechos. Los autores comentan que ésta es una patología no esperada en un individuo con los terceros molares apenas desgastados. Cook et al. (1983) identifican lesiones características de una distrofia vertebral de crecimiento (enfermedad de Scheuermann) entre los Australopithecus afarensis de 
Hadar (Etiopía), concretamente en AL-288 y AL-333. Ripamonti (1988) presenta un caso que sugiere una periodontitis infantil, una forma de enfermedad periodontal reconocida recientemente, que afecta a dientes decíduos después de la erupción general, hacia los 4 años de edad, donde un defecto funcional primario y patógenos periodontales específicos parecen ser los responsables del inicio y progresión rápida de la destrucción periodontal. Los signos sugestivos de este proceso aparecen en el ejemplar, atribuido a Australopithecus africanus, STs 24 de Sterkfontein, Transvaal, Pretoria, miembro 4 (2,5-3 Ma). El fragmento de maxilar derecho conserva el M1 superior y los molares decíduos, y alrededor de las raíces de estas dos últimas piezas muestra la mayor pérdida de hueso alveolar. Fisk y Macho (1992) describen una fractura por compresión del calcáneo izquierdo STW 363, Australopithecus africanus de Sterkfontein, miembro 4. La pieza presenta un fragmento adherido en la porción posterosuperior, que ha sido interpretado como la mitad del calcáneo fracturado, como resultado de una caída sobre el pié izquierdo. Los autores comparan este ejemplo con un caso clínico actual, donde el astrágalo aparece embebido dentro del calcáneo roto después de una fractura no reducida. La capacidad locomotora habría quedado limitada. Aunque muchos datos avalan en este caso la interpretación, los autores advierten sobre la posiblidad de que en la tomografía computerizada, que ha ayudado en el diagnóstico, se observen imágenes debidas a un proceso diagenético en la fosilización, citando estudios de otros autores sobre estas cuestiones. Depósitos y recristalización de calcita podrían imitar hueso trabecular, y esta posibilidad existe en homínidos fósiles plio-pleistocenos de Suráfrica acumulados en cuevas. Los autores concluyen ante este caso que no hay, aparentemente, una relación bien definida entre estilo locomotor y lesión, y que necesitan investigarse, por distintos métodos, cuestiones sobre morfología funcional y sus implicaciones en el modo de vida. Respecto a problemas dentales en australopitecos, Tobías (1974) cita la caries, que aparece ocasionalmente, como sucede en varios ejemplos de Swartkrans y en uno de Sterkfontein; el apiñamiento de dientes labiales, especialmente en formas robustas, como en A. robustus de Swartkrans, Transvaal, A. boisei de Peninj y en $\mathrm{OH} 5$, el holotipo de $A$. boisei, de Olduvai, Tanzania, que presenta además una ligera rotación en caninos superiores; algunas anomalías de forma y un marcado desgaste dental en muchos casos. La evidencia de hipoplasia de esmalte en $\mathrm{OH} 5$ induce a pensar al citado autor que, en tres ocasiones, este homínido sufrió trastornos sistémicos, sobreviviendo a aquellos episodios de enfermedad. En el homínido MLD 22, Australopithecus africanus de Makapansgat, Pretoria, se ha detectado un absceso alveolar en M1 inferior (Aguirre, 1970). White (1978), en un intento de cuantificar y considerar el significado de la hipoplasia dental entre los homínidos Plio-Pleistocenos surafricanos, encuentra una mayor frecuencia entre los australopitecos de Swartkrans que entre los de Sterkfontein. La frecuencia de individuos jóvenes en el primero de estos depósitos es significativamente mayor que en Sterkfontein. Aparte de que debe tenerse en cuenta que entre ambos australopitecos medían 1,5 Ma y que corresponden a especies $\mathrm{y}$, por lo menos, subgéneros distintos, el autor advierte sobre la necesidad de examinar los datos sobre hipoplasia en restos de homínidos surafricanos acumulados en cuevas a la luz de la información tafonómica, ya que no reflejan necesariamente la población biológica de la que proceden. Respecto al tan debatido tema sobre los célebres hundimientos craneales y fracturas sin signos de regeneración ósea entre estos homínidos, una vez superada la idea de violencia intraespecífica generalizada, se barajan las distintas posibilidades de lesión mortal o lesión post mortem, donde se invocan acciones intencionales o fortuitas, como accidentes naturales, canibalismo, ataque de carroñeros, o de carnívoros, especialmente leopardos (Tobías, 1974). Un ejemplo de lesiones mortales que orientan claramente hacia esta última posibilidad nos lo ofrece el cráneo juvenil SK 54, Australopithecus robustus de Swartkrans. Las marcas de armas punzantes observadas en ambos parietales se atribuyen concretamente a los caninos inferiores de un leopardo (Brain, 1993). Respecto a las marcas de dientes en $\mathrm{OH}$ 7, el holotipo de Homo habilis, que sugieren muerte violenta infligida por el ataque de un cocodrilo, podrían haber sido producidas después de la muerte.

Entre los restos de homínidos de Koobi-Fora, Kenya, se ha identificado enfermedad periodontal en KNM-ER-730, Homo erectus, u Homo ergaster, según algunos autores (Wood, 1992), datado en 1,6 Ma, y en KNM-ER-731. En este último, la destrucción de hueso a nivel de la raíz del canino puede atribuirse a un absceso apical (Lumley et al., 1982). Walter y Leakey (1993) reconocen asímismo una lesión periodontal a nivel de P4 y M1 inferiores derechos de la mandíbula perteneciente al más completo esqueleto hallado de antiguo homínido: KNM-WT 15.000, Homo erectus de Nariokotome (Kenya), excavado en sedimentos de 1,5 Ma. Corresponde a un niño de unos 11 años de edad que perdió la corona del segundo molar deciduo no mucho antes de la muerte, que pudo sobrevenir a consecuencia de una septicemia a partir de una infección de la encía. También se reconocen algunos signos de enfermedad periodontal entre los restos de Baringo, concretamente en la segunda mandíbula de Kapthurin, KNM-BK-8518 (Day, 1986). En el esqueleto parcial de Homo sp. ind. KNM-ER-803 procedente de sedimentos Plio-Pleistocenos al este del Lago Rodolfo, una falange distal del dedo I del pie tiene signos de artrosis en la superficie articular proximal, y en KNM-ER-164 aparecen unidas la $7^{\mathrm{a}}$ vértebra cervical y la $1^{\mathrm{a}}$ torácica, no en articulación anatómica correcta, ya que esta última está dislocada hacia la derecha e inclinada posteriormente (Day y Leakey, 1974). El esqueleto casi completo de Homo erectus KNM-ER-1808 de Koobi-Fora, Kenya, datado en al menos 1.6 Ma, presenta en los huesos largos, particularmente en los fémures y las tibias, un engrosamiento cortical notable a nivel de las diáfisis, por una reacción perióstica de tejido óseo muy tosco. El análisis morfológico e histológico ha permitido a Zimmerman (1981) proponer el diagnóstico de hipervitaminosis A, que atribuye al consumo excesivo de hígado crudo, especialmente de carnívoros, mucho más rico en esta vitamina que el de herbívoros (Walker et al., 1982).

La hemimandíbula de Kromdraai (Suráfrica) TM-1517 sufrió en la región incisival un proceso óseo que parece atribuible a reacción por causa de una lesión o tal vez una infección incipiente (Aguirre, 1970).

En la mandíbula de Lantian (China) se presenta un caso de agenesia dental, que afecta a P1 inferior derecho y terce- 
ros molares (Lumley et al., 1982). Woo (1964) atribuye la ausencia del primer bicúspide derecho a pérdida ante mortem, como a otras piezas perdidas del mismo lado.

La mandíbula de Pithecanthropus erectus C de Sangiran, Java (Indonesia), de hace más de 700.000 años, perdió el M1 inferior derecho poco antes de morir (Lumley et al., 1982). El hueso presenta signos de infección. El fragmento mandibular infantil Sangiran 21 tiene una fractura consolidada en mala posición, con un aplastamiento importante de fragmentos. Algunos traumatismos mortales sugieren violencia o accidente natural como los del Pithecanthropus $I V$ de Sangiran inferior (Weidenreich, 1945: 17), o la mandíbula de Glagahombo, Meganthropus B de Sangirán, que, según Von Koeningswald (1968) fue mordida por un cocodrilo (fide Aguirre, 1970).

\section{PLEISTOCENO MEDIO}

\section{África}

En la mandíbula de Tighenif III (Argelia), del Pleistoceno Medio antiguo, hay evidencia de un violento traumatismo y de regeneración ósea. El tumor de la mandíbula de Kanan, Kenya, atribuido clásicamente a un tumor maligno, podría haber sido benigno en opinión de Lumley et al. (1982). En la Calvaria de Salé (Marruecos), forma primitiva de Homo sapiens, Hublin, en 1985, observa que la región nucal muestra alguna anormalidad o carácter patológico (fide Day, 1986). En este homínido se aprecia un fuerte desgaste dental. Las estrías de descarnación del cráneo de Bodo (Etiopía) son lo más parecido a lesión experimental por aplicación de un instrumento cortante de piedra a un hueso fresco (White, 1986), y aunque representa una evidencia sólida a favor del canibalismo, no se conserva la base del cráneo, por lo que proporciona poca información sobre remoción del cerebro. Este autor recuerda la observación de Binford, en 1981, respecto a lo dudosos que resultan muchos de los casos considerados como evidencia de canibalismo en homínidos pleistocenos, citando neardentales de Krapina, Hortus, Engis, y otros muchos casos (Roper, 1969). Concretamente en Engis 2, las marcas producidas en el cráneo pueden interpretarse como una consecuencia de las actividades de restauración y manipulación (White y Toth, 1989). En el cráneo de Bodo, después de haberlo limpiado convenientemente, aparecieron más estrías de descarnación al lado de la órbita y sobre la bóveda (White, 1992). El cráneo de Broken Hill (Kabwe) muestra policaries, abscesos apicales, mastoiditis y proceso metastásico infeccioso que perforó el temporal izquierdo varios días antes de la muerte. Puech et al. (1980) sugieren falta de higiene y de habilidad técnica para desarrollar hábitos de limpieza.

\section{Asia}

La célebre excrecencia patológica en la porción posteromedial del tercio superior de la diáfisis del fémur del Pithecanthropus III de Trinil, Java, responde a una miositis osificante de origen traumático. El diagnóstico sugerido de fluorosis no es compatible con los resultados de la exploración microrradiográfica y por microscopía electrónica (Day y
Molleson, 1973). Como secuela post-traumática, se osificaron los tendones del músculo vastus medialis u otros tendones musculares que se insertan en esta región (Steinbock, 1976). Entre los cráneos de Ngandong, Java, en la calota Solo $\mathrm{V}$, dos hendiduras en el occipital sugieren muerte violenta (Lumley y Lumley, 1985). Varios casos más de fracturas en la base del cráneo en esta colección se atribuyen a signos inequívocos de canibalismo. Wolpoff (1980) comenta que es probable que las bases de los cráneos y las caras de Ngandong se rompieran con la intención de remover el cerebro.

En la mandíbula PA 86 de Zhoukoudian (Pekín) se perdió en vida el $\mathrm{I} 2$ inferior izquierdo, y la hipoplasia de esmalte se presenta en dos piezas dentarias entre un total de 147 dientes aislados figurados por Weidenreich en 1943. Las numerosas fracturas y señales de combustión de los 14 cráneos de Zhoukoudian pueden responder a una manifestación de violencia, canibalismo o accidentes naturales (Weidenreich, 1943). Lumley et al. (1982) citan lesiones traumáticas en los cráneos III, VI, X y XII.

\section{Europa}

El cráneo Aragó XXI (Tautavel, Francia) carece de P2 superior derecho por avulsión dentaria, seguramente de origen traumático, que tuvo lugar mucho antes de la muerte (Lumley et al., 1982). Smith (1977) supone que la ausencia de esta pieza se debe a agenesia, que también se observa en incisivos centrales inferiores en la mandíbula de Montmaurin. Entre los restos de Vértesszòllos (Hungría), datados en unos 350.000 años, Vértesszòllos II presenta estrías de descarnación en el occipital, en la zona de inserción de músculos cervicales, por lo que Ulbrich, en 1979, deduce que este homínido fue víctima del canibalismo (fide Day, 1986). Mallegni et al. (1983) describen los restos de homínidos mesopleistocenos del yacimiento achelense de Castel di Guido, cerca de Roma, cuya edad se ha estimado en torno a los 300.000 años. En una diáfisis de fémur izquierdo, C d G2 , una profunda punción cortical en la superficie posterior y superior, puede interpretarse como una marca de dientes de carnívoro, y en un fragmento de maxilar superior derecho, $\mathrm{C}$ d G-4, las imágenes radiográficas de las modificaciones patológicas que se observan en cavidades apicales y ápices de raíces son consistentes con cambios por inflamación granulomatosa crónica del tejido periodontal apical por exposición del canal pulpar. Si bien la pérdida de coronas dentales no permite saber si estos cambios fueron secundarios a un fuerte desgaste funcional o a caries dental, los autores se inclinan a pensar en una etiología funcional, teniendo en cuenta la rareza de caries en homínidos fósiles y la notable implicación del alvéolo de los incisivos.

Los homínidos mesopleistocenos de Atapuerca han sido objeto de sucesivos estudios paleopatológicos a medida que el material se ha ido recuperando en las campañas anuales de excavación. Se han identificado surcos de desgaste a nivel del cuello en dientes molares en relación con el hábito de introducir un objeto con función similar a la del palillo de dientes y con el padecimiento de gingivitis (Pérez et al., 1982; Bermúdez de Castro et al., 1987). Se han hecho estudios preliminares sobre patología dental y Líneas de Harris (Bermúdez de Castro y Rosas, 1986; Bermúdez de Castro, 1988). Queda pendiente un estudio sobre Líneas de Harris a 


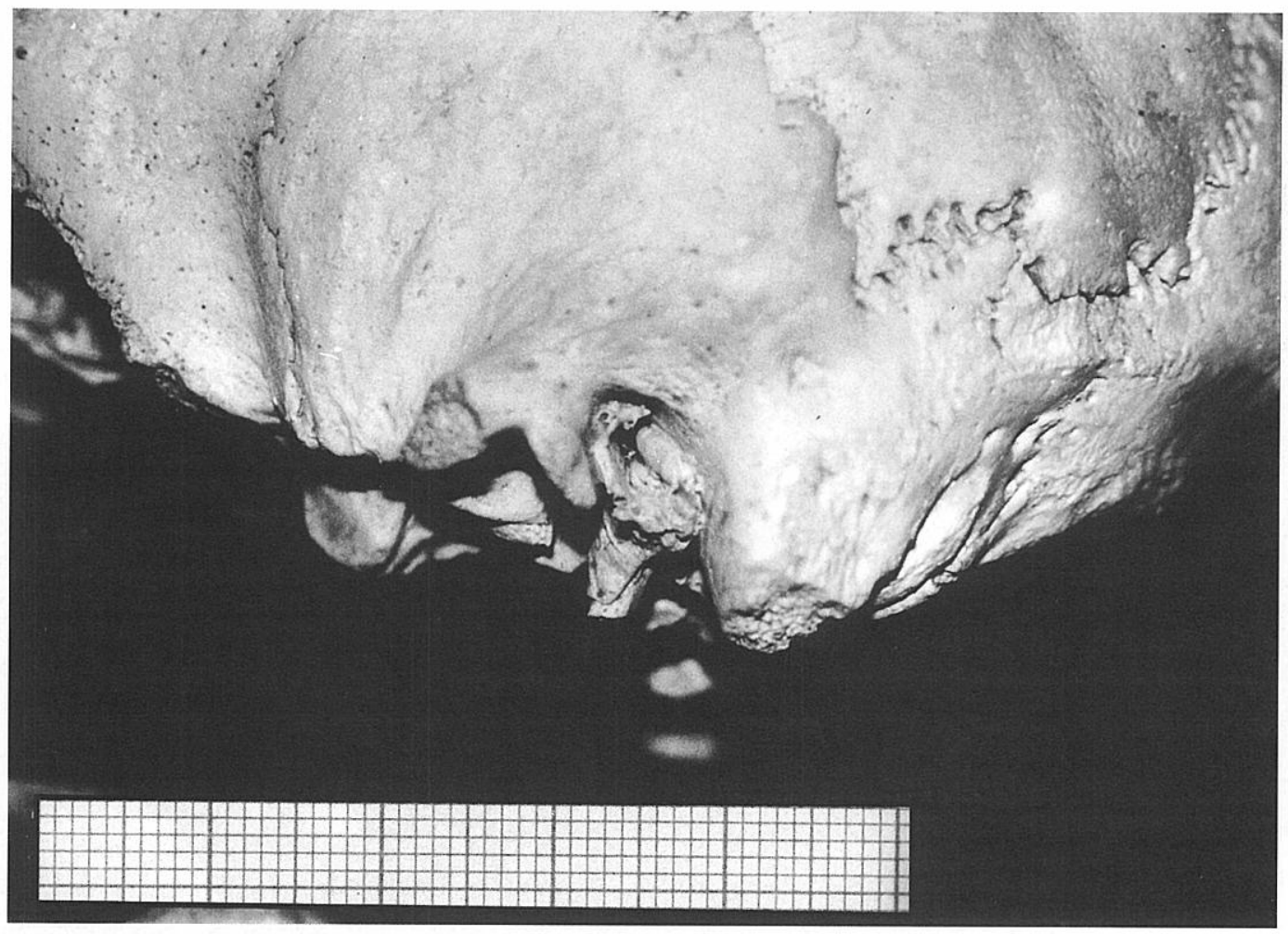

Figura 1. Cráneo 4. Homínido mesopleistoceno de la Sima de los Huesos (Atapuerca, Burgos). Adulto. Norma lateral izquierda. Hiperostosis del conducto auditivo externo.

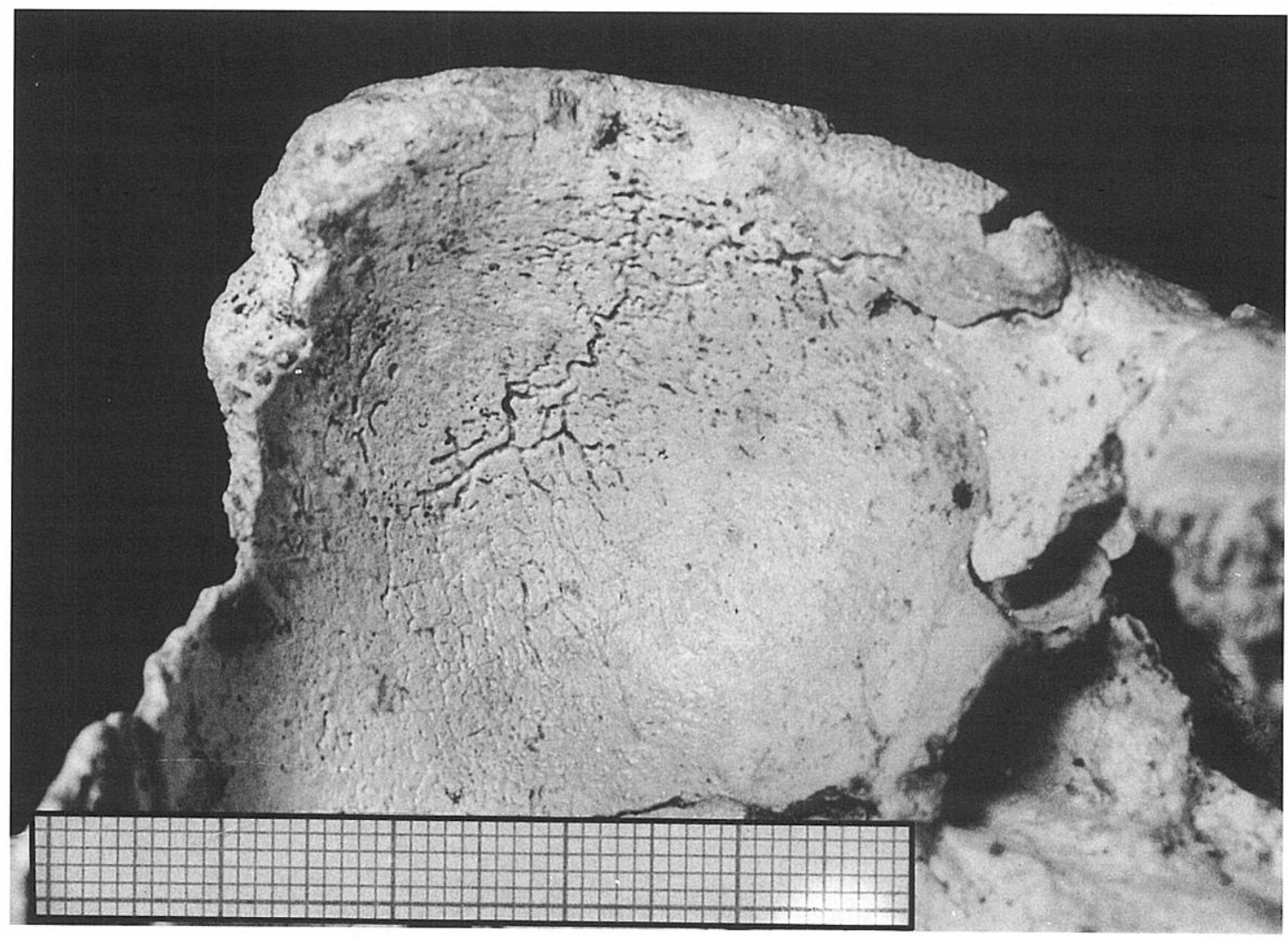

Figura 2. El mismo cráneo 4 de la figura 1 mostrando el techo de la órbita derecha. Cribra orbitalia. Categoría 4, según la clasificación de Webb (1989). 


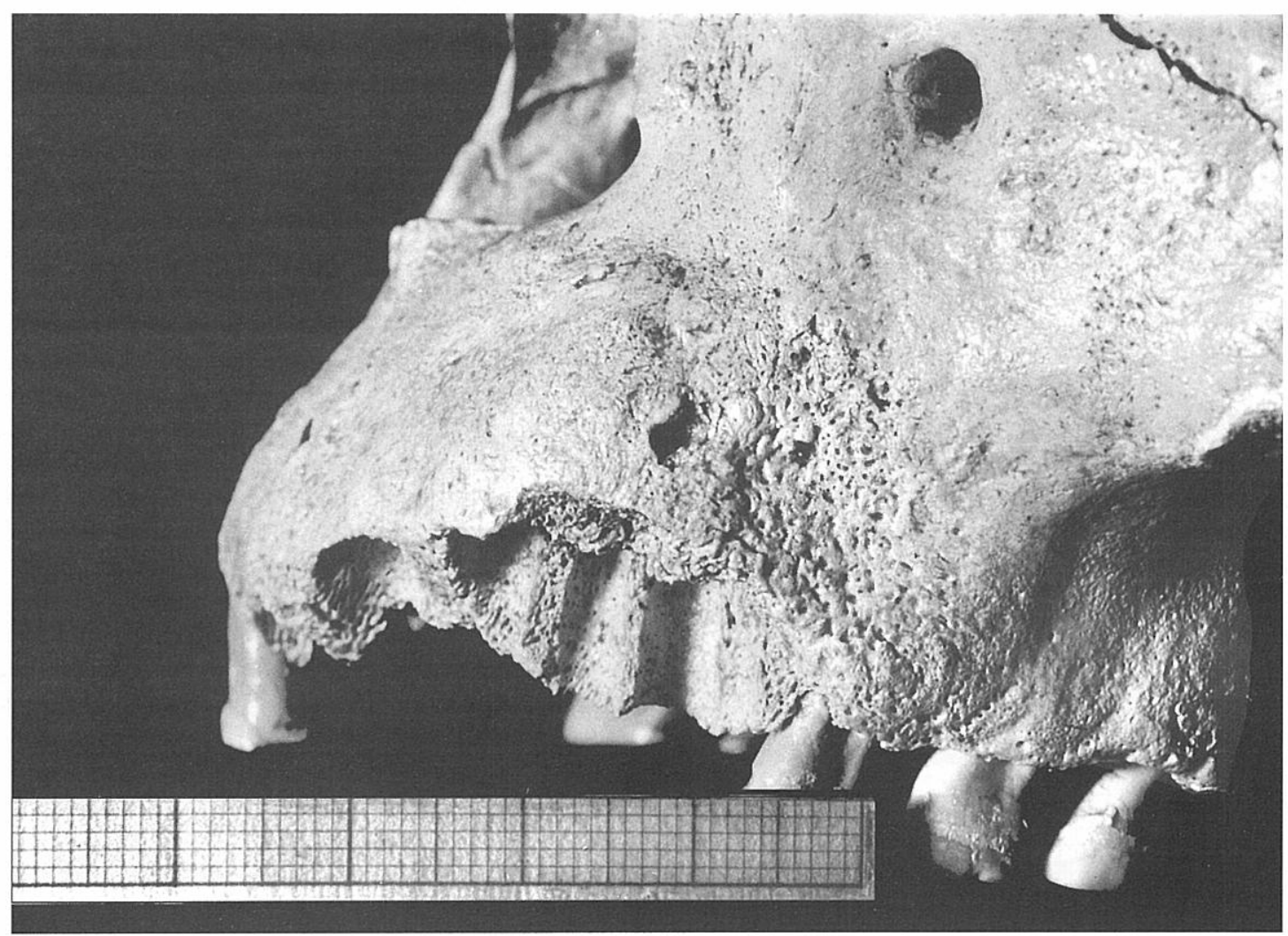

Figura 3. Cráneo 5 de la sima de los Huesos (Atapuerca, Burgos). Adulto. Osteítis maxilar en el lado izquierdo.

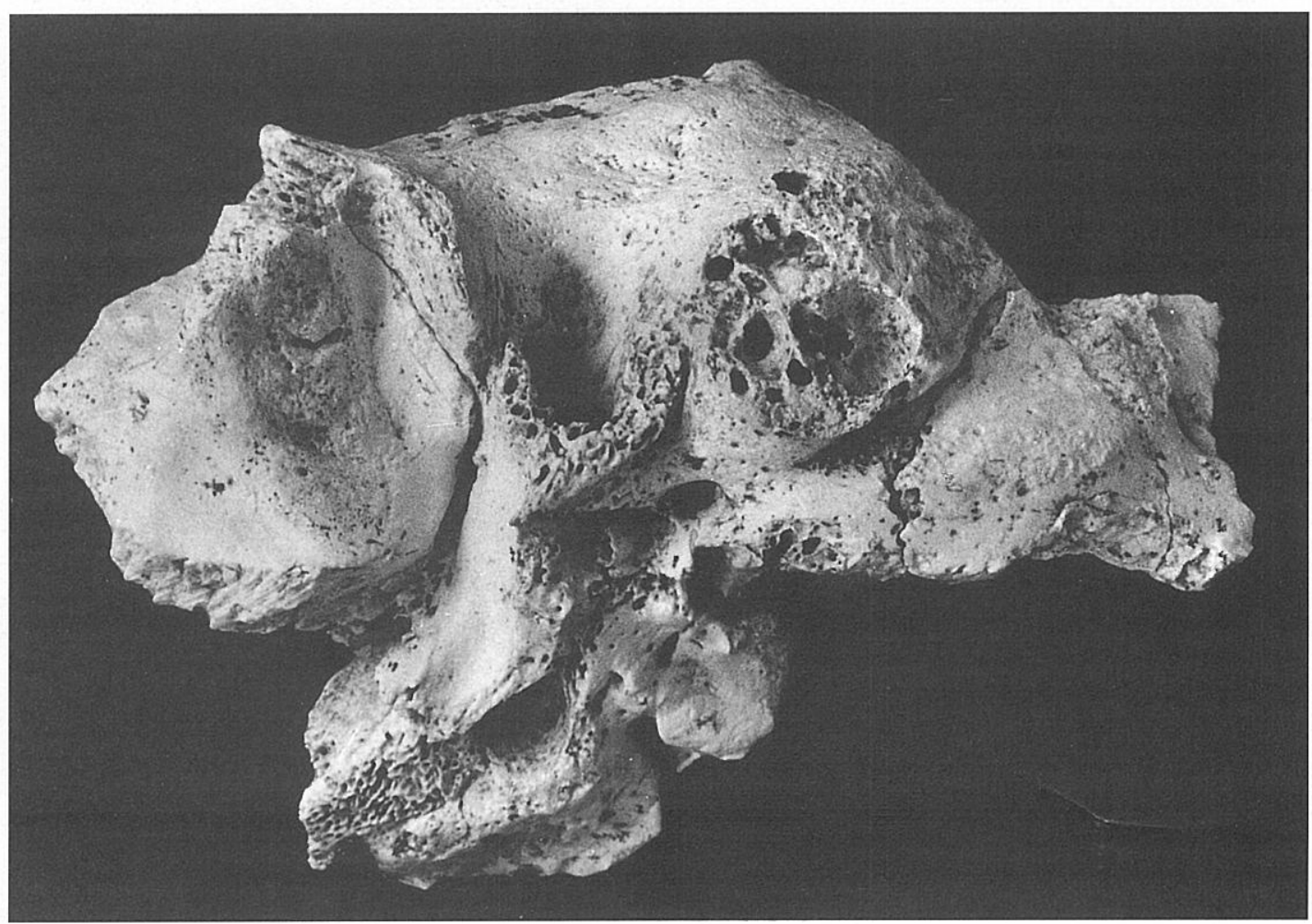

Figura 4. AT-418. Fragmento de hueso temporal izquierdo de individuo inmaduro de la sima de los Huesos (Atapuerca, Burgos) que conserva la región articular. Artropatía degenerativa temporomandibular. Este homínido sufrió este proceso patológico de forma bilateral. 
la vista del abundante material postcraneal, sobre todo de huesos largos recuperados desde estas primeras evidencias, donde se identificaron también casos de hipoplasia, hipercementosis y ligeros signos de cálculos dentales. Pérez et al. (en prensa) analizan y discuten los hallazgos de interés paleopatológico que ofrecen los cráneos 4,5 y 6 recuperados en la campaña de 1992, tres piezas clave que figuran entre el material más valioso y sin precedentes para los estudios sobre variabilidad y relaciones filogenéticas de las poblaciones humanas del Pleistoceno Medio. Las evidencias en estos cráneos se refieren a hiperostosis del conducto auditivo externo, cribra orbitalia, osteitis maxilar, traumatismos craneales banales y artropatía degenerativa temporomandibular. Estas dos últimas condiciones patológicas ya habían sido detectadas en la población; la última con frecuencia tan sorprendentemente alta que excede los límites conocidos en cualquier población humana. También sorprende el que la artropatía degenerativa la padecieran individuos inmaduros. En aquella fecha (1992) 6 individuos, entre 8 que conservaban la región articular del hueso temporal, sufrieron la artropatía, y desde entonces han aparecido nuevos casos, pendientes de estudio. En los 3 cráneos tratados aquí, 4, 5 y 6, los dos primeros de adultos y el tercero de un individuo juvenil, la afección es bilateral. La hiperostosis del conducto auditivo externo se presenta en el cráneo 4 de forma bilateral y muy simétrica en ambos conductos auditivos (Fig.1). La lámina timpánica ha sufrido una hiperostosis generalizada que se observa desde el margen externo del meato. La hiperostosis aparece enrollada dentro del canal del conducto auditivo externo, como resultado del engrosamiento de la lámina desde la sutura timpanomastoidea y timpanoescamosa, donde el engrosamiento es mayor. El crecimiento inusual del hueso timpánico casi ha obliterado el conducto auditivo. Estos caracteres morfológicos permiten el diagnóstico de osteomas del anillo timpánico descartándose, como era de esperar, la posibilidad de exostosis auditiva de etiología ambiental, de acuerdo con la hipótesis termal acuática (Kennedy, 1986). La cribra orbitalia se identifica en el cráneo 4 (Fig.2) y en 4 casos más, entre un total de 16 fragmentos de hueso frontal ( 5 individuos adultos, 5 inmaduros y 6 sin determinar). De los 4 individuos afectados, uno es juvenil y presenta las lesiones en estado incipiente, y 3 son adultos en fase de recuperación.

Estas lesiones son una manifestación leve de hiperostosis osteoporótica y serían la expresión de un episodio anémico ligero o de corta duración, muy posiblemente relacionado con malnutrición y/o parásitos intestinales. La osteitis maxilar diagnosticada en el cráneo 5 (Fig.3) afecta al proceso alveolar entre C y M1 superior izquierdos; se extiende por la cara externa hasta el borde nasal inferior y lateral, y en la cara interna ha originado una gran reacción ósea. En el extremo apical del P3 superior se observa un absceso con un poro de drenaje hacia la cara externa. La pieza no se conserva, pero no se perdió en vida. Este es uno de los pocos ejemplos de periodontitis apical en el Pleistoceno Medio.

Respecto a la artropatía degenerativa temporomandibular en los homínidos de Atapuerca (Fig.4), esta nueva evidencia en los 3 cráneos refuerza la hipótesis que venimos defendiendo de la relación entre este proceso patológico y los procesos evolutivos (Rosas y Pérez, 1944, a y b; Pérez, en prensa; Pérez y Martínez, en prensa). Concebida en un prin- cipio la patología desde una perspectiva clínica y biomecánica funcional de acuerdo con los planteamientos médicos habituales (Pérez, 1988; Pérez y Martínez, 1989; Pérez, 1989; Pérez, 1991), su alta frecuencia la venimos interpretando en términos biomecánicos pero desde un punto de vista totalmente distinto, donde se exploran las causas en el marco de un modelo de morfogénesis craneofacial (Rosas, 1992). La paleopatología puede así entenderse como una fuente de información paleobiológica para los estudios de las relaciones ontogenia-filogenia (Rosas y Pérez, 1994, a y b).

En la muestra dental de los homínidos mesopleitocenos de Atapuerca, la hipoplasia de esmalte ha podido estudiarse sobre un total de 89 dientes superiores, 143 inferiores y un decíduo, pertenecientes a un mínimo de 29 individuos, en un intento de determinar el nivel de estrés biológico que afectó a su desarrollo (Bermúdez de Castro y Pérez, 1995). Se ha estimado que la frecuencia por individuos en la muestra no fue superior al $40 \%$. La mayoría de las hipoplasias ocurrieron entre el nacimiento y los 7 años. Tanto la incidencia como la intensidad de las hipoplasias fueron significativamente menores que en neandertales. Los resultados sugieren que los homínidos europeos del Pleistoceno Superior antiguo probablemente sufrieron un incremento significativo de estrés biológico respecto a sus antecesores del Pleistoceno Medio. Pensamos que, como probables causas de estas evidencias de disrupciones ameloblásticas en Atapuerca procede pensar en problemas nutricionales, acaso agravados por infecciones parasitarias, basándonos en que también hay evidencia de anemia entre los individuos de esta población biológica (Pérez et al., en prensa).

Alférez y Roldán (1992) describen un M3 superior derecho procedente del yacimiento mesopleistoceno de Pinilla del Valle (Madrid). La pieza sufrió en vida un traumatismo que afecta al protocono y llega hasta la mitad de la raiz. El estudio, mediante analizador de imagen y radiográfico, induce a pensar que el individuo sufrió un golpe violento. Una lesión de estas características se produce cuando un diente antagonista choca contra él con una gran fuerza y con dirección de abajo hacia arriba y de derecha a izquierda. La lesión tuvo lugar años antes de la muerte. Por otra parte, la corona tiene numerosos puntos de hipoplasia.

En el parietal del niño de Lazaret (Niza), las modificaciones morfológicas evocan un meningioma, de evolución probablemente letal (Lumley et al., 1982). Puech y Albertini (1981) estudian en los dos dientes del hombre de Lazaret varias formas de hipoplasia menor distribuídas sobre la totalidad de la superficie de las coronas, que pueden deberse a contínuos disturbios en largos períodos, más que a disturbios episódicos. Los análisis microscópicos no permiten distinguir el límite entre los caracteres normales de la superficie de esmalte externa y los que pueden ser clasificados como patológicos. El radio de la Chaise-Suard (Charente, Francia) revela una artrosis en el codo (Lumley et al., 1982).

Entre los restos de Ehringsdorf se han identificado casos de piorrea alveolar e hipoplasia de esmalte; malposición dental en un M2 de un adolescente, calcificaciones en la cavidad pulpar de un incisivo por proceso inflamatorio y posibles alteraciones metabólicas (Patte, 1962). Señales de violencia se identifican en los cráneos de Fontéchevade, y en el de Steinheim cerca de Stuttgart, donde se evoca canibalismo ritual. 


\section{PLEISTOCENO SUPERIOR/HOLOCENO}

El cráneo de Tzeyang (China) sufrió una osteomielitis maxilar a partir de un absceso alveolar en la región molar izquierda (Chang, 1962).

Entre los restos de Krapina (Yugoslavia) se han identificado periodontitis, alteraciones radiculares en dientes, fractura de incisivos y consecuente osteitis periapical, cálculos, hipercementosis, artrosis temporomandibular, pseudoartrosis (o amputación?) en ulna derecha (Krapina 180), y desgastes en incisivos que hablan a favor de un uso de la dentición muy distinto al normal de cortar el alimento (Wolpoff, 1980). White (1986) ratifica la existencia de estrías de descarnación entre estos restos, donde están representados 20 individuos de ambos sexos, y cuyas lesiones incisas con sílex se vienen interpretando como maniobras de descarnación atribuídas a canibalismo. En el catálogo de Radovčić et al. (1988) ofrecen interés paleopatológico el fragmento de plano nucal 19.19 , con numerosas lesiones incisas paralelas; el fragmento frontoparietal izquierdo $20 . \mathrm{Pa} 4$, con una pequeña herida curada en la escama del frontal, también observada en la región astérica del parietal 34.7; la mandíbula I (K D P13), con pérdida en vida de P3 inferior izquierdo; la ulna derecha $180 \mathrm{~V} 2$, con pseudoartrosis; la ulna izquierda 188.8 con fractura curada, y otros casos patológicos sin especificar: escápula izquierda 130, con alteración en fosa glenoidea; clavícula 149; fragmento de diáfisis de fémur 257.24; patela derecha 215.3; falange proximal del pie 253.2 y vértebras cervicales 4 y 7 (siglas 106 y 109) del mismo individuo, con la imagen típica de una espondiloartrosis. En la imagen de la mandíbula I, la más completa, en los cóndilos parece identificarse una artrosis. Esto opina también Day (1986) refiriéndose a su morfología.

A Jacobs y Armelagos (1980) se debe una discusión acerca del estado actual de conocimientos sobre patologías demostradas en neandertales. Entre los de Shanidar (Iraq), las lesiones más frecuentes son de origen traumático. Trinkaus (1983) resume su patología, sobre la que había tratado previamente Stewart en distintas ocasiones, describiendo los traumatismos en detalle y citando la artrosis temporomandibular. La artrosis es muy frecuente en estos restos y, en la mayoría de los casos, según Trinkaus (1983) se debería a niveles excesivos de estrés biomecánico, si bien en muchas ocasiones fue consecutiva a traumas. Con frecuencia se observan también osificaciones de ligamentos. Shanidar I es un individuo politraumatizado con múltiples fracturas y artrosis como secuela. La lesión de la órbita izquierda pudo haber producido ceguera. La clavícula derecha tiene una lesión osteomielítica curada. La hipoplasia en clavícula, escápula y húmero derechos se debería a una hipotrofía por desuso. Este individuo fue manco, por malformación congénita (peromelia?), porque sufrió un traumatismo (pseudoartrosis?) o, como sugirió en 1959 Stewart, por amputación encima del codo, seguida de regeneración y larga supervivencia. También padeció una exostosis auditiva como respuesta ósea a irritación del canal acústico externo. En este individuo se atribuye un mayor uso de los dientes como herramienta, a falta de brazo derecho, y se supone que murió por un desprendimiento de roca, como también parece poder deducirse en Shanidar 5 y en Shanidar 3. Este último, cuando murió dentro de la cueva, se estaba recuperando de una herida de lanza en sus costillas. También padeció artrosis, igual que Shanidar 2. Trinkaus y Zimmerman (1982) en su descripción de los traumatismos que sufrieron en vida los neandertales adultos de Shanidar 1, 2, 4 y 5 concluyen que parece haber sido característica de los neandertales una alta frecuencia de traumatismos asociada a supervivencia de los individuos heridos. La frecuencia de traumatismos es mayor en neandertales que en poblaciones humanas modernas.

Trinkaus (1982) aporta un nuevo dato respecto a los neandertales de Shanidar (Iraq): los contornos que exhiben las bóvedas craneales de Shanidar 1 y 5 sugieren que fueron artificialmente deformados. Esta es, según el autor, la interpretación más razonable, después de considerar otras distintas posibles causas de la deformación como menos probables. Las diferencias entre los resultados de la deformación en ambos cráneos probablemente reflejan, de acuerdo con el citado autor, diferencias en la posición y duración de la presión aplicada.

Rothschid y Thillaud (1991) identifican enfermedad por depósitos de pirofosfato cálcico en esqueletos de neandertales de dos yacimientos muy alejados entre sí: Shanidar y La Chapelle-aux-Saints. Esta es la documentación más antigua de esta enfermedad en el hombre, y teniendo en cuenta su carácter familiar, los autores deducen que las poblaciones de estos dos lugares pueden estar más estrechamente relacionadas de lo que previamente se ha supuesto. En un tercio de los individuos de la Chapelle-aux-Saints y en el 17\% de los de Shanidar hay alteraciones típicas de esta enfermedad en muñecas y tobillos, descartándose en el diagnóstico diferencial la artrosis y la artritis reumatoide. Si fue familiar en neandertales, como ocurre actualmente, la hipótesis de Trinkaus, de que los restos de Shanidar están más estrechamente relacionados con otros neandertales del próximo oriente que con los europeos, puede ser cuestionada.

Crubezi y Trinkaus (1992) identifican en Shanidar I lesiones osteofíticas en las vértebras y esqueleto apendicular que parecen independientes de las lesiones traumáticas múltiples y de la enfermedad degenerativa articular. Estas lesiones afectan a los cuerpos vertebrales de L3 y L5, a ambas tuberosidades calcáneas y olecranon ulnar izquierdo. Estas manifestaciones soportan el diagnóstico de caso leve de enfermedad hiperostósica.

Agelarakis (1993) ha realizado un estudio paleoepidemiológico sobre la población de la cueva de Shanidar, donde queda demostrado que el uso integrado de la paleopatología sirve como un único y poderoso medio para descifrar perspectivas de condiciones humanas prehistóricas.

Entre los restos de Monsempron (Francia) se ha observado un caso de hipercementosis en raíces de dientes inferiores, asociada a un fuerte toro mandibular que parece, más que patológico, estar en relación con una hiperactividad masticatoria (Dastugue y Lumley, 1976). Estos autores mencionan el primer vestigio de agenesia en Francia, que afecta a los incisivos laterales de la mandíbula de Malarnaud. En Hortus se han identificado estrías de descarnación (White, 1986) y defectos de esmalte en los segundos molares superiores del individuo III (Bermúdez de Castro y Rosas, 1986). En la Ferrasie I una artropatía crónica afectó a la articulación sacroilíaca izquierda; en el trocánter mayor derecho se produjo una osificación postraumática de la extremidad distal del tendón del obturador externo, y en el codo derecho, con 
deformación y osteofitos, se supone que sufrió un traumatismo (Dastugue y Lumley, 1976). También hay evidencia de artropatía degenerativa temporomandibular, en el cóndilo izquierdo. En el esqueleto femenino de la Ferrasie II se aprecia sacralización parcial de la $5^{\mathrm{a}}$ vértebra lumbar, genu valgum bilateral y posible osteomielitis de la infancia en la diáfisis del peroné.

En la Chapelle-aux-Saints se han identificado periodontitis supuradas, espondiloartrosis, sobre todo cervical, artrosis coxofemoral y temporomandibular, fractura de ulna y exostosis auditiva. Dastugue y Lumley (1976) atribuyen la deformación del acetábulo del célebre hombre de la Chapelle a subluxación congénita de cadera. También presenta patella bipartita. Con respecto a la sugerencia del comportamiento altruista entre los neandertales, al deducirse que el "hombre viejo" de la Chapelle era desdentado y el alimento tendría que haber sido expresamente preparado para él, Tappen (1985) concluye que esto no está demostrado, ya que probablemente tenía dientes funcionales y en oclusión. La pérdida en el maxilar superior de incisivos, canino y primer premolar fue probablemente debida a un absceso o tumor maligno, pero esto pudo presentarse poco antes de la muerte, teniendo en cuenta que la destrucción ósea por estas causas puede tener lugar en muy poco tiempo.

Aguirre (1970) cita una mandíbula juvenil de Le Moustier que sufrió disfunción en la muda de un canino inferior, y en la erupción de los últimos molares, posible causa de dolores muy agudos. En la Quina se han descrito un traumatismo en cráneo y cara, doble fractura de $\mathrm{I} 2$ y C superiores izquierdos a consecuencia de la penetración de un cuerpo extraño entre ambas piezas durante la masticación, y surcos de desgaste dental en el cuello por el uso de "palillo de dientes" (Martin, 1923). Straus y Cave en 1957 diagnosticaron una artrosis temporomandibular grave en ambos cóndilos mandibulares (Aguirre, 1970) y Trinkaus (1983) cita una herida en el brazo izquierdo de la Quina 5 que produjo hipoplasia o atrofia del húmero. Lorenzo Lizalde (1994) encuentra alteraciones generalizadas de los periquimata como indicadores de perturbaciones durante la gestación en el P3 superior infantil Gal 4A.245.26 de la cueva de los Moros de Gabasa (Huesca), musteriense. En otra pieza, $M_{1}$ derecho Gal Rev.303, un surco de desgaste a nivel del cuello evidencia el uso del "palillo de dientes" y un problema gingival. En el parietal de Cova Negra, Játiva (Valencia), Fusté (1953) describe un traumatismo que se manifiesta por una reacción cicatricial de tejido óseo. Lumley (1973) deduce hematoma subperióstico y posible arrancamiento de la aponeurosis epicraneal. En la mandíbula de Bañolas (Gerona) Lumley (1972) encontró un desgaste dental extremo, una fuerte inclinación del plano oclusal y deformación de la arcada dentaria. Recientemente esta mandíbula ha sido objeto de un minucioso estudio con muchas colaboraciones (Maroto et al., 1993) que ha aportado nuevas conclusiones sobre desgaste dental, patología, dieta, hábitos higiénicos y culturales. Spitery (1983) cita como hidrocéfalo un cráneo infantil neandertal(?) de Starocelje (Crimea).

Ogilvie et al. (1989) estudian la hipoplasia dental, como indicador inespecífico de estrés durante el desarrollo, en 669 dientes de Neandertales, encontrando una frecuencia del $36,0 \% ; 41,9 \%$ en dientes permanentes y 3,9\% en decíduos. La hipoplasia afectó al 75\% de los individuos, una frecuen- cia realmente alta, de donde deducen los autores altos niveles de estrés durante el desarrollo, que sería primariamente nutricional, comenzando con el destete y continuando a través de la adolescencia.

Respecto a hombres anatómicamente modernos, entre los restos de Israel, en el yacimiento musteriense de Qafzeh (Palestina) se ha diagnosticado hallux valgus (Dastugue, 1982) y en Skhul V (Monte Carmelo, Palestina) abscesos apicales severos.

En Obercassel (Alemania) aparece la osteoartritis; en Combe-Capelle, bloques cervicales congénitos (Dastugue y Lumley, 1976); en un esqueleto de Solutré, espondilosis; en Laugerie-Basse una fractura de maléolo interno. Respecto a las lesiones óseas generalizadas del esqueleto del hombre de Cro-Magnon 1, Thillaud (1985) emite el diagnóstico de histiocitosis X diseminada, al observar que el examen radiográfico no es compatible con una actinomicosis, como había sido diagnosticado anteriormente. La lesión del cráneo femenino del abrigo de Cro-Magnon $\mathrm{n}^{\circ} 2$, producida por un golpe seco y fuerte con arma cortante de piedra sobre el frontal izquierdo tiene indicios de infección y curación que no debió de progresar. Según Janssens (1970) la supervivencia fue de unos 12 a 16 días. En Abri Pataud se han citado dientes supernumerarios de forma y dimensiones aberrantes en una mujer joven, abscesos y osteitis maxilar, y en un niño de unos 5 años (n³) un M2 superior mal orientado. En el hombre de Chancelade, hallux valgus (Dastugue, 1982) y fractura temporoparietal derecha que evoca un traumatismo de la infancia, y en uno de los esqueletos de Grimaldi, hipoplasia de esmalte.

Borgognini et al. (1980) encuentran en dientes y fragmentos mandibulares de niveles gravetienses de la Gruta Paglicci, Rignano Garganico (Wurm III), una patología dental similar a la descrita por Brabant en el Paleolítico superior europeo. Una frecuencia muy elevada de periodontitis apical crónica acompañada eventualmente por la formación de un granuloma, está en relación con el desgaste dental precoz y muy acentuado, y con los traumatismos. La pérdida en vida de los últimos dientes se atribuye a la evolución progresiva del desgaste y a inflamación perirradicular. Sólo hay un ejemplo de caries, de cuello, estando de acuerdo esta baja frecuencia con lo que es la norma en el Paleolítico superior, donde lo más frecuente son las artrosis y las fracturas consolidadas. La mayor incidencia de traumatismos denota comportamiento agresivo. García Sánchez (1960) informa sobre estrías de descarnación entre los restos de humanos del nivel 2 de la Carigüela III (Piñar, Granada). Las incisiones lineales se presentan en forma de pequeñas estrías paralelas producidas artificialmente, como las descritas por Vallois en tres mandíbulas del Auriñaciense final de la Gruta de Isturitz. Otros hallazgos de la misma cueva de la Carigüela sugieren prácticas antropofágicas, cumplimiento de un rito funerario, o construcción de trofeos, según el citado autor. Czarnetzi (1990) describe las alteraciones patológicas de dos individuos del Auriñaciense antiguo de Stetten (Alemania). Stetten I, con artrosis temporomandibular, fusiones vertebrales (origen genético, traumático o degenerativo?) y parodontosis y, en este individuo, igual que en Stetten II, hiperostosis osteoporótica como manifestación de anemia por parásitos o malnutrición. En Stetten II, una depresión casi circular que no puede atribuirse a una fovea granularis, en la superficie inter- 
na del parietal izquierdo, en la región del bregma y, próximo a este signo, un ligero adelgazamiento de la esponjosa en la superficie externa. El autor piensa, como únicas razones posibles, en un quiste, un meningioma, o un defecto congénito en la osificación. Guerrero Sala y Lorenzo Lizalde (1981) describen varios surcos paralelos en el borde oclusal del incisivo RaXD 180.000, asociado a industria magdaleniense, de la cueva de Rascaño (Santander), datado en algo más de 14.000 años, y atribuyen estas lesiones a una actividad extrafisiológica de tipo no definido. Spiteri (1983:90) menciona un caso más de hidrocefalia en Rocherei III, también magdaleniense.

Brennan (1987) estudia la hipoplasia de esmalte en el Paleolítico francés, ofreciendo nuevos datos sobre las relaciones entre los cambios biológicos y culturales a nivel regional y poblacional desde hace aproximadamente 100.000 años hasta 10.000 años. Según este autor, resultados preliminares sugieren que la hipoplasia, casi inexistente en el Paleolítico inferior, incrementa dramáticamente en la transición al Paleolítico medio y, de nuevo, en la transición al Paleolítico superior. Cada uno de los cuatro períodos del Paleolítico superior muestra distintas frecuencias. Las transiciones inferiormedio medio-superior parecen haber sido acompañadas de un incremento de estrés biológico. En los períodos culturales que siguen a la transición entre el medio y superior, de acuerdo con el autor, el estrés varía considerablemente, dependiendo de la afiliación cultural. Respecto al resultado preliminar de la casi inexistencia de hipoplasia en el Paleolítico inferior pensamos que, como ha sucedido con los homínidos mesopleistocenos de Atapuerca (Bermúdez de Castro y Pérez, 1995), la observación microscópica permitirá detectar casos de hipoplasia moderada en este período cultural.

Frayer et al. (1988) presentan un caso de enanismo condrodistrófico en un yacimiento del Paleolítico superior, concretamente en un esqueleto, entre dos recuperados, en la cueva Romito, cerca de Papasidero (Cosenza) en Calabria, Italia. La antigüedad atribuida a este resto es de unos 10.000 años.

Formicola et al. (1990) presentan un caso de ausencia bilateral de trocánter menor del fémur en un esqueleto perteneciente a un individuo masculino de unos 25 años, procedente de la cueva de Arene Candide, en el NO de Italia, de finales del Paleolítico superior. Los autores piensan, ante este defecto, que podría tratarse de un carácter epigenético o bien deberse a una avulsión traumática bilateral. Respecto a la primera posibilidad, sería una condición congénita extremadamente rara no descrita anteriormente. En el segundo caso, sería resultado de un excesivo estrés muscular.

La evidencia de trepanaciones prehistóricas comienza en el Epipaleolítico. Dastugue (1975) aporta dos ejemplos de trepanación incompleta en el yacimiento norteafricano de Afalow-bou-Rhumel (Argelia). También aquí aparece hallux valgus (Dastugue, 1982). Metz (1977) advierte que la escoliosis no es extraña en los pueblos antiguos de ninguna época, y refiere un ejemplo de una sepultura mesolítica de Rochereil, con rotación de piezas vertebrales alrededor de su eje. También en Rochereil se presenta la hidrocefalia (Dastugue y Lumley, 1976). Spitery (1983) cita otro caso de hidrocefalia en un niño mesolítico (Ofnet K 1805).

Boroneant (1993) describe dos enterramientos preneolíticos del $6^{\circ}$ y $7^{\circ}$ milenios antes de J.C. En uno de ellos (sepul- tura M39) se conservan dos puntas de flecha en el hueso que penetraron en el espacio intercostal. En el Neolítico abundan las señales de heridas craneales por flechas, piezas lanzadas con honda, y golpes. Spitery (1983) cita otro caso de hidrocefalia en un niño del Neolítico portugués.

En niveles del Neolítico antiguo, en tiempos de la civilización de la cerámica cardial, hace aproximadamente 5.000 años, se practicó el canibalismo. Gallay (1991) describe incisiones en una mandíbula de la Gruta de Gardon en Ambérien-en-Bugey, Ain, que demuestran que se seccionó el músculo masetero. Este autor refiere que estos restos son contemporáneos de los de la gruta de Fontbregona, en el mediodía francés donde el canibalismo parece probado, por el hallazgo de huesos de animales y humanos acumulados en pequeñas fosas con señales típicas de descuartizamiento sistemático.

En Normandía, en el túmulo neolítico de La Hoguette, cerca de Fontenay-le-Marmion, Calvados, de hace 5.000 años, se presenta la espondiloartritis anquilopoyética (Dastugue, 1982). En la necrópolis de Loisy-en Brie (Neolítico final) estudiada en 1975 por Comode (Dastugue y Lumley, 1976) se identificaron anomalías congénitas, como manifestación del atlas en el occipital, bloques vertebrales, vértebras de transición en la región lumbosacra, espina bífida, escoliosis, etc. La frecuencia de caries crece con las primeras aglomeraciones agrícolas, y el desgaste dental es mucho menor.

No hay cita segura de infecciones específicas en los hombres del Paleolítico, y es a partir de la revolución agrícola-ganadera, hace 7-8 milenios, cuando se produce la gran explosión de la enfermedad infecciosa. A partir de entonces crece el interés por seguir el curso y evolución de la enfermedad en relación con los acontecimientos históricos.

Con respecto al continente americano, existe una abundante bibliografía sobre la evidencia paleopatológica de anemia en la prehistoria, atribuída fundamentalmente a las deficiencias en hierro y proteínas derivadas de la adopción de una economía agrícola basada en el maíz. Trinkaus (1977) aporta el primer caso de anemia registrado en una población no predominantemente agrícola, procedente del yacimiento precerámico peruano de Alto Salaverry, cuya causa estaría en la dieta o influencias de parásitos. Esta última es una explicación alternativa a la que atribuye como factor más importante de la anemia el déficit alimenticio, como asímismo lo sugiere el que la anemia fuera común en poblaciones prehistóricas con dieta basada en recursos marinos, rica en hierro y aminoácidos esenciales (Walker, 1986). En todo caso, debe tenerse presente, como se concibe actualmente, el papel que la hipoferremia puede jugar en defensa de los individuos de una población frente a la carga patogénica de su medioambiente.

Entre los homínidos fósiles de Oceanía (Day, 1986) figuran como patológicas la mandíbula de Mungo III, perteneciente a un individuo masculino adulto-maduro con artritis y enfermedad dental, pérdida de dientes y reabsorción alveolar; y entre los restos de Kow Swamp, los cráneos K55 y K57 son dos de los ejemplos australianos de deformación artificial.

Webb (1988) estudia dos cráneos de aborígenes australianos que sugieren trepanación quirúrgica. Estos serían los primeros casos registrados en Australia, pues si bien estas intervenciones ya se conocían en Oceanía, la evidencia provenía de Melanesia. 
Webb (1989) estudia la paleopatología de aborígenes australianos anteriores a la llegada de los europeos, analizando poblaciones del Pleistoceno (Kow Swamp, Coobool, Crossing, Cohuna..) y del Holoceno. Además de traumatismos, infecciones y procesos degenerativos encuentra, como indicadores de estrés, cribra orbitalia, hipoplasia de esmalte y líneas de Harris. Un estudio comparativo entre las poblaciones pleistocenas de Murray Valley con los grupos más recientes de la misma región refleja las consecuencias de las modificaciones de los factores socioeconómicos durante el Holoceno en el estado de salud, observándose principalmente una mayor frecuencia de anemia e infecciones en la época más reciente. Numerosos casos de traumatismos evidencian un comportamiento agresivo. Al mismo autor (Webb, 1990) se debe un estudio exhaustivo sobre el llamativo engrosamiento craneal de un homínido australiano de "Villandra Lakes", de finales del Pleistoceno superior, (WLH 50) cuya morfología describe en términos de una condición patológica asociada a las modernas discrasias sanguíneas hemolíticas. El autor advierte que este ejemplo no es igual a otros dos casos citados de engrosamientos en algunas regiones de la bóveda craneal, también de finales del Pleistoceno superior de Australia, concretamente en Kow Swamp (9.000-12.000 años) y Coobool Creek (12.000 años) que, por otra parte, no han sido adecuadamente descritos. La imagen radiográfica del cráneo WLH 50 revela una hiperostosis hematopoyética y sugiere que el individuo sufrió una anemia severa. Aunque los cambios esqueléticos en este caso no son exactamente los que se observan hoy en las anemias de origen genético, el autor defiende una etiología genética y la interpreta en términos de adaptación biológica, considerando el hecho de que, en su forma heterocigótica, algunas variantes de hemoglobina determinadas genéticamente confieren un grado de inmunidad a la malaria. A pesar de que esta enfermedad no fue endémica en la Australia prehistórica, y de la completa ausencia de hemoglobinas anormales entre grupos aborígenes recientes, el autor se pregunta si la malaria y sus patologías asociadas podría haber existido en Australia hace más de 30.000 años, desaparecido en el Holoceno.

Molnar y Molnar (1990) observan que los aborígenes australianos contemporáneos muestran, como las poblaciones prehistóricas, una considerable variación en los patrones y tasas de desgaste dental. Los trabajos de estos autores en contemporáneos permiten una mejor interpretación sobre el grado de influencia que distintas variables morfológicas de la arcada dental ejercen sobre el desgaste. En este caso se cuenta con la ventaja de poder conocer directamente los demás factores (biológicos, dietéticos, culturales) que influyen en este desgaste dental.

\section{COMENTARIO FINAL}

Cualquier intento de aproximación al conocimiento de la patocenosis (término definido por Grmek (Capaso, 1984)), o conjunto de todas las enfermedades de una población antigua, entraña una gran dificultad, mayor aún en el caso de homínidos fósiles, por insuficiencia de fuentes de información y sesgo de las muestras analizadas. No obstante, como refleja esta síntesis, es posible muchas veces valorar los cambios en las relaciones cualitativas y cuantitativas de las enfer- medades de las distintas poblaciones a través del tiempo a partir de los datos epidemiológicos que de estas poblaciones pueden extraerse.

En una dimensión temporal, en las modificaciones experimentadas en la patocenosis han influído, necesariamente, los procesos evolutivos, tanto humanos como de los microorganismos patógenos; los cambios en los sistemas de organización humana y, en definitiva, el conjunto de cambios medioambientales. Las diferencias cualitativas y cuantitativas entre las enfermedades de cada población están en relación con las variables que determinan la morbilidad y, la paleopatología, en su concepción más amplia, no sólo nos informa sobre la naturaleza de las entidades nosológicas, sino también sobre estas variables a las que puede accederse desde muy distintas vías de investigación que dan cuerpo a la paleoecología. Por otra parte, en los estudios comparativos con indicadores de estrés biológico, como la hipoplasia de esmalte dental, las diferencias entre los niveles de estrés en distintos períodos han demostrado ser, asímismo, un fiel reflejo de los cambios biológicos y culturales, como demuestran los resultados obtenidos por Brennan (1987) en el paleolítico francés y por Bermúdez de Castro y Pérez (1995) entre los homínidos mesopleistocenos de Atapuerca y los neandertales.

Por otra parte, la presente recopilación exige reconsiderar una vez más que, ante las dificultades de la paleopatología al verse obligada a formular diagnosis retrospectivas, hay una falta de adecuación de diagnósticos médicos en la interpretación de antiguas lesiones, lo que exige disponer de un vocabulario estandarizado para la descripción de lesiones osteoarqueológicas. Considerando que en estos últimos años la Paleopathology Association viene realizando grandes esfuerzos en este sentido, y que ya es posible, en gran medida, disponer de una terminología descriptiva propia, se hace patente la necesidad, en muchas ocasiones de actualizar las aportaciones bibliográficas sobre descripciones paleopatológicas en homínidos fósiles en vistas a los estudios comparativos entre poblaciones en los distintos contextos bioculturales.

\section{AGRADECIMIENTOS}

Al Prof. Emiliano Aguirre, por sus recomendaciones para la mejora del manuscrito original.

Este trabajo ha sido subvencionado por la Dirección General de Investigación Científica y Técnica. Proyecto PB93-0066-C03-01 (D.G.I.C.Y.T.).

\section{BIBLIOGRAFÍA}

Agelarakis, A. 1993. Paleopathology and manifestations of stress at the dawn of sedentary life: the Homo sapiens population of the Shanidar cave. Papers on Paleopathology presented at the Twentieth Annual Meeting. Paleopathology Association, 1314 April Toronto, Ontario.

Aguirre, E. 1970. Enfermedades y accidentes de los primeros humanos. Publicaciones del Departamento de Paleontología, 12, 24 pp, Universidad Complutense de Madrid.

Alférez, F. y Roldán, B. 1992. Un molar humano anteneandertal con patología traumática procedente del yacimiento cuaternario de 
Pinilla del Valle (Madrid). Munibe (Antropologia-Arkeologia), supl. n. ${ }^{\circ}$ 8, 183-188, San Sebastián.

Bermúdez de Castro, J.M. 1988. Dental diseases and Harris Lines in the fossil human remains from Atapuerca-Ibeas (Spain). Journal of Paleopathology, 1, 131-146.

Bermúdez de Castro, J. M., Arsuaga, J. L. y Pérez, P. J. 1987. Anomalías de desgaste cervical en molares humanos de Atapuerca. En: El hombre fósil de Ibeas y el Pleistoceno de la Sierra de Atapuerca. (Aguirre, E., Carbonell, E. y Bermúdez de Castro, J.M., Eds.), I. Cap. XX, Junta de Castilla y León, Consejería de Cultura y Bienestar Social, 359-366.

Bermúdez de Castro, J. M. and Pérez, P. J. (1995). Enamel hypoplasia in the Middle Pleistocene Hominids from Atapuerca (Spain). American Journal of Physical Anthropology, 96, 301-314.

Bermúdez de Castro, J. M. and Rosas, A. 1986. Dental Pathologies and Lines of increased density in fossil Hominids from Atapuerca (Burgos, Spain). IV European Meeting of the Paleopathology Association. Univ. Complutense, Madrid, 1986, 277-284.

Borgognini Tarli, S. M., Fornaciari, G. et Palma di Cesnola, A. 1980. Restes humains des niveaux gravettiens de la grotte Paglicci (Rignano Garganico). Contexte archéologique, etude anthropologique et notes de Paleopathologie. Bulletin et Mémoires de la Societé d'Anthropologie de Paris, T.7 Série XIII, 125-152.

Boroneant, V. 1993. Nouvelles données sur les découvertes anthropologiques de Schela Cladovei a drobeta turní Severin (Roumanie). L'Anthropologie (Paris), Tome 97, n. ${ }^{\text {s }}$ 2/3, 511-514.

Brain, C. K. 1993. A Taphonomic Overview of the Swartkrans Fossil Assemblages. En: Swartkrans. A Cave's Chronicle of Early Man. C.K. Brain, Ed., Transvaal Museum Monograph. No.8, Pretoria.

Brennan, M. V. 1987. Dental hypoplasias in the French Paleolithic. Papers on Paleopathology presented at the Fourteenth Annual Meeting. Paleopathology Association, 1-2 April, New York. Abstract: 13.

Capasso, L. 1984. "Pathocenosis": a new approach to study the relationship between health and human evolution. Antropologia Contemporanea, Italian Journal of AnthropologyVol. 7, $\mathrm{n}^{\circ} 2$. $4^{\text {th }}$ Congress of the European Anthropological Association, Florence, 4-7 September 1984. Abstracts: 3.

Chang, K. Ch. 1962. New evidence of fossil man in China. Science, 136, 749-760.

Cook, D. C., Buikstra, J. E., Rousseau, C. J. and Johanson, D. C. 1983. Vertebral Pathology in the Afar Australopithecines. American Journal of Physical Anthropology, 60, 83-101.

Crubezi, E. and Trinkaus, E. 1992. Shanidar 1: A case of Hyperostotic Disease (DISH) in the Middle Paleolithic. American Journal of Physical Anthropology, 89, 411-420.

Czarnetzki, A. 1980. Pathological changes in the Morfology of the young paleolithic skeletal. Remains from Stetten (South-West Germany). Journal of Human Evolution, 9, 15-17.

Dastugue, J. 1975. Pathologie des hommes épipaléolithiques d'Afalou-bou-Rhummel (Algérie). L'Anthropologie (Paris), 79(3), 483-506.

Dastugue, J. 1982. Las enfermedades de nuestros antepasados. Mundo Científico, 19, 1132-1141.

Dastugue, J. et Lumley, M. A. de, 1976. Les Maladies des Hommes Préhistoriques. La Préhistoire Francaise C.N.R.S., Paris, 153164, 614-622.

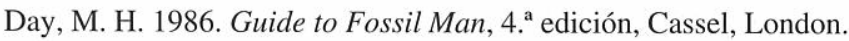

Day, M. H. and Leakey, E. F. 1974. New evidence of the Genus Homo from East Rudolf, Kenya (III). American Journal of Physical Anthropology, 41, 367-380.

Day, M. H. and Molleson, T. 1973. The Trinil Femora. Human Evolution, XI, 127-154.

Fisk, G. R. and Macho, G. A. 1992. Evidence of a Healed Compression fracture in a Plio-Pleistocene Hominids Talus from Sterkfontein, South Africa. International Journal of Osteoarchaeology, 2, 325-333.

Formicola, V., Frayer, D. W. and Heller, J. A. 1990. Bilateral absence of the Lesser Trochanter in a late Epigravettian Skeleton From Arene Candide (Italy). American Journal of Physical Anthropology, 83(4), 425-437.

Frayer, D. W., Macchiarelli, R. and Mussi, M. 1988. A case of Chondrodystrophic Dwarfism in the Italian Late Upper Paleolithic. American Journal of Physical Anthropology, 75, 549565.

Fusté, M. 1953. Parietal neandertalense de Cova Negra (Játiva). Diputación Provincial de Valencia, Servicio de Investigación Prehistórico, Serie Trabajos Varios n. ${ }^{\circ}$ 17, Valencia, 32 pp. + 4 láms.

Gallay, A. 1991. El hombre neolítico y la muerte. En: Orígenes del hombre moderno. Selección e introducción de Jaume Bertranpetit, Libros de Investigación y Ciencia, 124-133.

García Sánchez, M. 1960. Restos humanos del Paleolítico Medio y Superior del Neo-Eneolítico de Piñar (Granada). Trabajos del Instituto Bernardino de Sahagún de Antropología y Etnología, Vol. XV, n. ${ }^{\circ} 2,17-72$ + 6 láms.

Guerrero Sala, L. A. y Lorenzo Lizalde, J. I. 1981. Antropología física en Rascaño. En: El Paleolítico Superior en la Cueva de Rascaño (Santander). Centro de Investigación y Museo de Altamira. Monografías, n. ${ }^{\circ}$ 3, Santander, 279-321.

Jacobs, K. H. et Armelagos, G. J. 1980. Les maladies des neandertaliens: Le role de la Paleopathologie dans l'interpretation d'une adaptation prehistorique. Papers on Paleopathology presented at the Third European Members Meeting of the Paleopathology Association, 26-28 September 1980, Caen, France. Abstract: C10.

Janssens, P. A. 1970. Palaeopathology. Diseases and Injuries of Prehistoric Man. John Baker, London.

Kennedy, G. E. 1986. The Relationship Between Auditory Exostoses and Cold Water: A Latitudinal Analysis. American Journal of Physical Anthropology, 71, 401-415.

Lumley, H. and Lumley, M. A. de, 1985. The diffusion of man in ancient world. Homo erectus. In: Homo Journey to the origins of Man's History. Four Million Years of Evidence. Cataloghi Marsilio s.r.l. Venezia, 60-74.

Lumley, M. A. de, 1972. La mandíbula de Bañolas. Diputación Provincial de Barcelona. Instituto de Prehistoria y Arqueología. Monografías XXXVII, Barcelona, 91 pp.

Lumley, M. A. de, 1973. Anténéandertaliens et néandertaliens du basin Méditerranéen Occidental Européen. Etudes Quaternaires, 2, Univ. de Provence, Centre Saint-Charles, Marseille.

Lumley, M. A. de, Spitery, E. et Mafart, B. 1982. Pathologie des Homo erectus. I Congrés International de Paléontologie Humaine, Nice, 16-21 Oct. 1982, T.I., 471-488.

Lorenzo Lizalde, J. I. 1994. Ensayo de una metodología aplicada al estudio de la Paleontología humana de las poblaciones prehistóricas del Valle Medio del Ebro. Tesis Doctoral, Universidad de Zaragoza, Departamento de Ciencias de la Tierra, Paleontología. 
Mallegni, F., Mariani-Costantini, R., Fornaciari, G., Longo, E. T., Giacobini, G. and Radmilli, A. M. 1983. New European Fossil Hominid Material From an Acheulean Site Near Rome (Castel Di Guido). American Journal of Physical Anthropology, 62, 263-274.

Maroto, J., Ed., 1993. La mandíbula de Banyoles en el context dels fóssils humans del Pleistocè. Centre d'investigacions arqueològiques, Girona 13, Sèrie Monogràfica, 194 pp.

Martín, H. 1923. L'Homme Fossile de La Quina. Doin, París, 260 pp.

Metz, F. 1977. Du diagnostic des scolioses in Paléopathologie. Thèse Médicine, Caen, 157 pp.

Molnar, S. and Molnar, I. M. 1990. Dental Arch Shape and Tooth Wear Variability. American Journal of Physical Anthropology, 82, 385-395.

Ogilvie, M. D., Curran, B. K. and Trinkaus, E. 1989. Incidence and Patterning of Dental Enamel Hypoplasia Among the Neandertals. American Journal of Physical Anthropology, 79, 25-41.

Patte, E. 1962. La dentition des Néanderthaliens. Masson, Paris.

Pérez, P. J. 1988. Evidencia de artritis temporomandibular en el hombre fósil de Ibeas (Sierra de Atapuerca, Burgos). I Reunión Nacional de la Asociación Española de Paleopatología, Logroño, 3 Junio 1988, 43-47.

Pérez, P. J. 1989. Paleopatología del hombre fósil de Ibeas (Sierra de Atapuerca, Burgos). VI Congreso Español de Antropología Biológica. Bilbao, septiembre 1989. Actas/Proceedings, Universidad del País Vasco, 403-411.

Pérez, P. J. 1991. Evidence of Disease and Trauma in the Fossil Man from Atapuerca-Ibeas (Burgos, Spain). International Journal of Osteoarchaeology, I, 253-257.

Pérez, P. J. (1995). Etiopatogenia de las lesiones temporomandibulares en los homínidos de Atapuerca. Etiopathogeny of the temporomandibular lesions in Atapuerca hominids. En: Evolución humana en Europa y los yacimientos de la Sierra de Atapuerca. Human evolution in Europe and the Atapuerca Evidence. Jornadas Científicas/Workshop, Castillo de la Mota. Medina del Campo. Valladolid, 1992: 333-341.

Pérez, P. J., Arsuaga, J. L. and Bermúdez de Castro, J. M. 1982. Atypical toothwear in fossil man. Paleopathology Newsletter, 39, 11-13.

Pérez, P. J. and Martínez, I. 1989. Evidence of temporomandibular arthrosis in the Middle Pleistocene Human Fossils from Atapuerca/Ibeas (Spain). Journal of Paleopathology, 3(1), 15-18.

Pérez, P. J. yandMartínez, I., en prensa. Temporomandibular arthrosis in Human Fossils from the Middle Pleistocene site of Atapuerca/Ibeas (Spain). IXth European Meeting of the Paleopathology Association, 1st-4th September 1992, Barcelona.

Pérez, P. J., Martínez, I. y Gracia, A., en prensa. Paleopatología de los fósiles humanos mesopleistocenos de la Sima de los Huesos (.Sierra de Atapuerca, Burgos) recuperados en la Campaña de 1992. II Congreso Nacional de Paleopatología, Universidad de Valencia, 7-10 Octubre 1993.

Puech, P. F. and Albertini, H. 1981. Enamel Pits of the Lazaret Man. Journal of Human Evolution, 10, 449-452.

Puech, P. H., Albertini, H. and Mills, N. T. W. 1980. Dental Destruction in Broken Hill Man. Journal of Human Evolution, 9 , 33-39.

Radovčić, J., Smith, F. H., Trinkaus, E. and Wolpoff, M. 1988. The Krapina hominids. An Illustrated Catalog of Skeletal Collection. Mladost, Zagreb, Yugoslavia. Croatian Natural History Museum.
Ripamonti, U. 1988. Paleopathology in Australopithecus africanus. A suggested case of a 3-Million-Year-Old Prepubertal Periodontitis. American Journal of Physical Anthropology, 76, 197-210.

Roper, M. K. 1969. A survey of the evidence for intrahuman killing in the Pleistocene. Current Anthropology, 10(4), 427-459.

Rosas, A. 1992. Ontogenia y filogenia de la mandíbula en la evolución de homínidos. Aplicación de un modelo de morfogénesis a las mandíbulas de Atapuerca. Tesis Doctoral, Facultad Ciencias Biológicas, Universidad Complutense de Madrid.

Rosas, A. y Pérez, P. J. 1994a. Evidencias en el sistema maxilofacial de los homínidos de Atapuerca/Ibeas de tendencias patológicas derivadas de factores construccionales. Apuntes sobre nuevas perspectivas en Paleopatología. En: Biología de las Poblaciones Humanas: Problemas metodológicos e interpretación ecológica. Actas del VIII Congreso de la Sociedad Española de Antropología Biológica (Madrid, septiembre 1993). Ediciones de la Universidad Autónoma de Madrid, 35-40.

Rosas, A. y Pérez, P. J. 1994b. Tendencias patológicas en el sistema maxilofacial de los homínidos de Atapuerca/Ibeas. Apuntes sobre nuevas perspectivas en Paleopatología. Coloquios de Paleontología, n. ${ }^{\circ}$ 47, Editorial Complutense, Madrid, 1994, 133-143.

Rothschid, B. M. and Thillaud, P. L. 1991. Oldest bone disease. Nature, 349, $\mathrm{n}^{\circ}$ 6307, 288.

Smith, P. 1977. Regional variation in tooth size and Pathology in Fossil Hominids. American Journal of Physical Anthropology, 47, 459-466.

Spitery, E. 1983. Paleoecologie de L'Homme Fossile. 6. La Paleontologie des Maladies Osseuses Constitutionnelles. Editions du CNRS, Marseille.

Steinbock, R. T. 1976. Paleopathological Diagnosis and Interpretation. Bone Diseases in Ancient Human Populations, Thomas, Springfield, $423 \mathrm{pp}$

Tappen, N. C. 1985. The dentition of the "Old Man" of the Chapelle-Aux-Saints and Inferences Concerning Neandertal Behavior. American Journal of Physical Anthropology, 67, 43-50.

Thillaud, P. L. 1985. L'Homme de Cro-Magnon et ses maladies. En: Histoire et Archéologie. Les maladies de nos ancèstres, ${ }^{\circ}$ 97, Sept. 1985, 28 F., 67-73.

Tobias, P. V. 1974. Aspects of Pathology and Death among early Hominids. The Leech, 44(3), 119-124.

Trinkaus, E. 1977. The Alto Salaverry Child: A case of Anemia from the Peruvian Preceramic. American Journal of Physical Anthropology, 46, 25-28.

Trinkaus, E. 1982. Artificial Cranial Deformation in the Shanidar 1 and 5 Neandertals. Current Anthropology, 23(2), 198-199.

Trinkaus, E. 1983. The Shanidar Neandertals. Academic Press, New York

Trinkaus, E. and Zimmerman, M. R. 1982. Trauma Among the Shanidar Neandertals. American Journal of Physical Anthropo$\log y, \mathbf{5 7}, 61-76$.

Walker, P. L. 1986. Porotic Hyperostosis in a Marine-Dependent California Indian Population. American Journal of Physical Anthropology, 69, 345-354.

Walker, A. and Leakey, R., Eds., 1993. The Nariokotome Homo erectus Skeleton. Springer-Verlag, Berlin, Heidelberg, 457 pp. 
Walker, A., Zimmerman, M. R. and Leakey. R. E. F. 1982. A possible case of Hipervitaminosis A in Homo erectus. Nature, 296, 248-250.

Webb, S. G. 1988. Two Possible Cases of Trephination From Australia. American Journal of Physical Anthropology, 75, 541-548.

Webb, S. G. 1989. Prehistoric stress in Australian Aborigines. A Paleopathological Study of a hunter-gatherer population. BAR 490, 197 pp.

Webb, S. G. 1990. Cranial thickening in an Australian Hominid as a possible Paleoepidemiological Indicator. American Journal of Physical Anthropology, 82, 403-411.

Weidenreich, F. 1943. The skull of Sinanthropus pekinensis. A comparative study on a primitive hominid skull. New Series D, 10, $485 \mathrm{pp}$.

Weidenreich, F. 1945. Giant Early Men From Java and South China. Anthropological papers of the American Museum of Natural History, New York, 40, Part.I, 1-134.

White, T. D. 1978. Early Hominid Enamel Hypoplasia. American Journal of Physical Anthropology, 49, 79-84.

White, T. D. 1986. Cut marks on the Bodo Cranium: A case of prehistoric Defleshing. American Journal of Physical Anthropology, 69, 503-509.
White, T. D. 1992. Prehistoric Canibalism. At Mancos 5MTUMR234. Princeton University Press, New Jersey, 462 pp.

White, T. D., Suwa, G., Hart, W. K., Walter, R. C., Wolde Gabriel, G., Heinzelin, J. de, Clark, J. D., Asfaw, B. and Vrba, E. 1993. New discoveries of Australopithecus at Maka in Ethiopia. Nature, 333, 261-265.

White, T. D. and Toth, N. 1989. Preparation Damage, Not Ancient Cutmarks. American Journal of Physical Anthropology, 78, 361-367.

Wolpoff, M. 1980. Paleoanthropology, Alfred A. Knopf, New York.

Woo, J. K. 1964. Discovery of the mandible of Sinanthropus lantianensis in Shensi Province, China. Current Anthropology, 5, 98-101.

Wood, B. 1992. Origin and Evolution of the genus Homo. Nature, 355, 783-790.

Zimmerman, M. R. 1981. Homo erectus and hipervitaminosis A. Annual Meeting of the Paleopathology Association, 22 April 1981, Detroit, Michigan, 2.

Manuscrito recibido: 22 de diciembre, 1994 Manuscrito aceptado: 29 de julio, 1995 